\title{
As políticas do arquivo em Thomas Elsaesser
}

\author{
Marcio Telles \\ https://orcid.org/0000-0003-3968-0739 \\ I - UFES \\ Vitória (ES). Brasil
}

\section{ELSAESSER, T. Cinema como}

\section{Arqueologia das Mídias.}

Trad. Carlos Szlak, São Paulo:

Edições Sesc, 2018, 320 p.

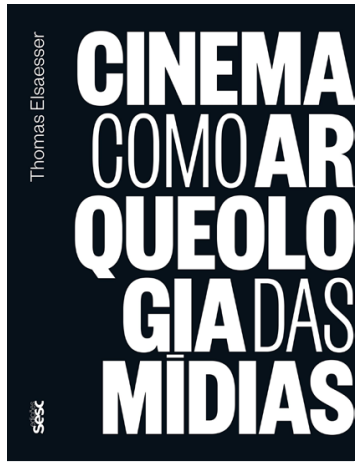

Resumo: Em recente coletânea que dá um panorama da obra deste prolífico autor alemão, o destaque é para as possibilidades de discussão teórica sobre o que é, afinal, a arqueologia das mídias. A proposta de uma abordagem que aspira à descrição do que estava ao redor dos filmes, evitando a cronologia linear, revela um profundo compromisso político contra o "mal de arquivo": encontrar, no passado, alternativas para o futuro.

Palavras-chave: arqueologia das mídias; arquivo; memória.

Abstract: The politics of archiving in Thomas Elsaesser - In a new collection that gives perspective to this prolific German author's work, the highlight is the possibility of theoretical discussion about what is, after all, Media Archaeology. Suggesting an approach that depicts what was around the films in a given moment in time and avoiding altogether any linear chronology, Elsaesser reveals a political commitment against what Derrida calls "archive fever". He aims to find in the past alternatives for the future.

Keywords: media archaeology; archive; memory.

A recente coletânea Cinema como arqueologia da mídia publicada pelo Sesc São Paulo é um bom ponto de entrada para o trabalho do prolífico teórico alemão Thomas Elsaesser (1943-) e, não menos, para as discussões teóricas a respeito da arqueologia das mídias, sobretudo porque ele é o responsável por cunhar o termo em 1990 (ELSAESSER, 1990). Revisitando a carreira após sua recente aposentadoria da Universidade de Amsterdã, 
o autor sustenta que batizar sua proposta de "arqueologia das mídias" pareceu natural quando quis sugerir uma abordagem que aspirasse à descrição do que estava ao redor dos filmes e evitasse qualquer cronologia linear. Como nota outro "mídia-arqueólogo", Siegfried Zielinski,

O que se encontra nessa história [a arqueologia das mídias], análogo a esporos, galhos quebrados, fezes, ou peles e plumagens perdidas, foi produzido inteiramente por meios culturais e técnicos. Ao procurar, coletar e classificar, o arqueólogo atribui significados; e esses significados podem ser totalmente diferentes daqueles que os objetos tinham originalmente (ZIELINSKI, 2006, p. 42).

A arqueologia das mídias deve respeitar as descontinuidades e estudar o "[...] pars pro toto do fragmento, que dá ao presente acesso a um passado" (idem, p. 186). A disposição da sala de projeção (capítulo 3); o comportamento do público (capítulo 4); a forma das narrativas (capítulo 5); os dispositivos científicos, médicos, militares e de monitoramento (capítulo 6); as teorias cinematográficas (capítulo 2) e as epistemologias desviantes (capítulo 7) servem para apontar a moldura geral na qual a mídia cinema estava inscrita. Amplia-se o leque das "materialidades da comunicação" (FELINTO, 2001) para além do mero suporte. Nas pesquisas de Elsaesser, repetidas vezes é o filme que se torna o "centro ausente" da pesquisa1. "O propósito", diz ele, "é alcançar um entendimento mais complexo do motivo pelo qual certos eventos básicos ocorreram" (p. 50).

Logo, "[...] um arqueólogo das mídias percebe o que está ausente ou o que foi suprimido" (p. 186). Elsaesser brinca que essa metodologia poderia ser chamada de "cão que não latiu", inspirando-se no conto de Sir Arthur Conan Doyle. Abrem-se as possibilidades de pesquisas históricas que se situem entre "a contra-história e 'história contrafactual'" (p. 50), criando conjecturas sobre o que "podia ter acontecido, em vez do que realmente aconteceu" (p. 50). Mas, como adverte o historiador britânico Neil Ferguson (1999, p. 18, tradução minha), outro entusiasta das "histórias virtuais", a abordagem contrafactual possui algumas armadilhas, como "[...] a tendência de confiar na inspiração, ou de postular explicações redutoras, o que leva à implausibilidade [e] a tendência a fazer suposições anacrônicas". Mesmo essas dificuldades não irão impedir Elsaesser (p. 50) de desejar "[...] devolver a um passado específico [...] seu próprio futuro: não aquele que a história subsequentemente lhe conferiu, [...] mas sim um futuro imaginado [...], vaticinado [...] e fantasiado" no período.

O desejo de restaurar a um passado o seu futuro reveste-se de missão política, sobretudo quando o "arquivo" é trazido à centralidade do debate, como nesta passagem:

1 Cf. ELSAESSER, 2000 para um exemplo monográfico desse tipo de estudo "arqueológico" de um filme-Metropolis de Fritz Lang - feito a partir da investigação dos roteiros, scripts de produção, locais de exibição, fragmentos de crítica, relatos de assistência e a comparação "material" entre os vários cortes existentes. 
Hoje em dia, o arquivo molda nossa visão do passado de modo mais decisivo do que a história, pois ele sempre nos permite revisitar e, assim, reescrever o passado, para engendrar a engenharia reversa de nosso presente, criando um futuro diferente como resultado do arquivo (p. 53).

Para Elsaesser e outros "mídia-arqueólogos", a facilidade crescente de manipular o "arquivo", única instanciação do passado, acaba por colocar em risco o futuro. Afinal, se o passado/arquivo inexiste a não ser nas memórias das máquinas, nossa única maneira de acesso a ele é através das tecnologias de mídia (ERNST, 2018). Essa redução da "construção da realidade" às condições de possibilidade dos suportes midiáticos é uma das características centrais da chamada teoria alemã das mídias (TELLES, 2017; TELLES, 2019).

Se, à primeira vista, parece mais uma demonstração de determinismo tecnológico, uma observação mais aguda aponta para a herança de Derrida (2001), que já observara que tanto "arquivo" quanto "arqueologia" prescrevem a exterioridade da memória. Como significam dois princípios - um físico/ontológico (o local de origem/natureza das coisas) e outro legal/nomológico (o local a partir do qual o líder comanda) - o arquivo e a arqueologia designam "ao mesmo tempo o começo e o comando" (DERRIDA, 2001, p. 11, grifos no original). Na Grécia Antiga, o local do arquivo era também a casa do arconte, aquele que comandava. No mundo hodierno, o local do arquivo são os servidores e os bancos de dados das Big Tech. Esse é o "mal de arquivo": a conjugação da história, da verdade e do poder àquele ou aqueles que o detém.

Por exemplo, Jussi Parikka (2017), um dos mais renomados mídia-arqueólogos, sugere que a narrativa progressista que termina nos ambientes ultratecnológicos de Google e Apple são a consequência, e não a causa, das Big Tech possuírem os meios de produção de memória. Como demonstra Elsaesser no presente volume, a arqueologia das mídias é tão obsessiva em resgatar passados descartados pela história oficial, afinal, as evidências negativas poderiam mostrar que "[...] os motivos pelos quais determinados eventos não ocorreram estão nos dizendo algo importante a respeito do que sim, aconteceu" (p. 50). Por isso mesmo, Zielinski (1996, online, tradução minha), ainda nos anos 1990, elegera como objetivo da arqueologia das mídias a missão de descobrir os "caminhos secretos da história que possam nos ajudar a encontrar o rumo para o futuro". Urge reivindicar o arquivo.

Marcio Telles é professor do Departamento de Comunicação da Universidade Federal do Espírito Santo. É doutor em Comunicação e Informação pela Universidade Federal do Rio Grande do Sul, com estágio sanduíche na Winchester School of Art, Universidade de Southampton, Reino Unido.

tellesjornal@gmail.com 


\section{Referências}

DERRIDA, J. Mal de arquivo: uma impressão freudiana. Trad. Cláudia de Moraes Rego. Rio de Janeiro: Relume Dumará, 2001.

ELSAESSER, T. Early Cinema: From Linear History to Mass Media Archaeology. In: ELSAESSER, T. (Org.). Early Cinema: Space Frame Narrative. Londres: BFI, 1990, p. 11-28.

. Metropolis. Londres: BFI, 2000.

ERNST, W. Arqueografia da midia: método e maquina versus história e narrativa da midia. In: BASTOS, M.; ALY, N. (Orgs.). Audiovisual experimental: Arqueologias, diálogos, desdobramentos. São Paulo: Pontocom, 2018, p. 23-50.

FELINTO, E. Materialidades da Comunicação: Por um Novo Lugar da Matéria na Teoria da Comunicação. Ciberlegenda, n. 5, Rio de Janeiro, RJ: 2001.

FERGUSON, N. Virtual History: alternatives and counterfactuals. Cambridge, RU: Basic Books, 1999.

PARIKKA, J. Arqueologia da Mídia: interrogando o novo na artemídia. Trad. M. Telles e L. Müller. Intexto, n. 39, p. 201-214, maio/ago. 2017.

TELLES, M. Des/Re/Escrevendo a história dos meios de comunicação: quatro contribuições a partir das Arqueologias das mídias. Dispositiva, Belo Horizonte, v. 7, n. 12, p. 101-116, jan. 2019.

Medium/forma nas teorias alemãs das mídias: exterioridade, a priori tecnológico-medial, corporalidade, presença e Kulturtechnik. Verso e Reverso, v. 31, p. 173-181, 2017.

ZIELINSKI, S. Arqueologia da mídia: em busca do tempo remoto das técnicas do ver e do ouvir. Trad. Carlos Szlak. São Paulo: Annablumme, 2006.

.Media Archaeology. CTheory, 7 de novembro de 1996. Disponível em: www.ctheory.net/ articles.aspx?id=42. Acessado em 7 de agosto de 2018. 